\title{
Impact of Mesenchymal Stem Cells on Lipopolysaccharide-Induced Apoptosis in Acute Lung Injury Rat Model
}

\author{
A. Hanaa - Mansour ${ }^{1}$, Maha G. Soliman², Wedad A. Hasan', \\ Rasha A. El - Sayed ${ }^{2}$ and Nahla A. Hassaan ${ }^{2 *}$ \\ ${ }^{1}$ Department of Pharmacology, National Organization for Drug Control and Research \\ (NODCAR), Giza, Egypt \\ ${ }^{2}$ Department of Zoology, Faculty of Science, Al-Azhar University, Cairo, Egypt
}

*Corresponding author

\begin{tabular}{l} 
K e y w o r d s \\
$\begin{array}{l}\text { Acute lung injury, } \\
\text { Mesenchymal stem cells, } \\
\text { Dexamethasone, } \\
\text { Lipopolysaccharide, } \\
\text { rMuc-5AC mRNA gene }\end{array}$ \\
Article Info \\
$\begin{array}{l}\text { Accepted: } \\
\text { 06 May } 2018 \\
\text { Available Online: } \\
\text { 10 June } 2018\end{array}$ \\
\hline
\end{tabular}

A B S T R A C T

Acute respiratory distress syndrome (ARDS) is among the most common causes of respiratory failure in critically ill patients. Despite extensive research, ARDS remains a major cause of morbidity and mortality, with no effective pharmacological treatment options. The present study was conducted to evaluate the efficacy of bone marrow-derived stem cells (BM-MSCs) compared with Dexamethasone (Dex) and Sodium bicarbonate $\left(\mathrm{NaHCO}_{3}\right)$ against acute lung injury (ALI) induced by lipopolysaccharide (LPS) in rats. Rats were injected with $20 \mu \mathrm{l}$ of LPS of Escherichia coli in each nostril for two consecutive days. Treatments were carried out by administration of BM-MSCs $\left(1 \times 10^{6}\right.$ cells/rat $)$, Dexamethasone (2mg/kg/i.p.) once before induction with LPS and sodium bicarbonate (10-15 ml/day for two consecutive days, while last dose was given 30 minutes before LPS inhalation). Treatment with BM-MSCs significantly decreased inflammatory influx, total leukocyte count in peripheral blood, reduction in oxidative stress, reversed depleted GSH in lung tissue, reduced inflammatory responses in rat nasal airways as detected by mucin rMuc-5AC gene expression in lung tissue when compared with LPS group. Moreover, BM-MSCs displayed signs of lung recovery and the severity of lung injury was significantly reduced when compared to the LPS group and restoring the normal histological picture of lung as well as apoptosis.

\section{Introduction}

Acute lung injury (ALI), characterized by unbalanced inflammatory responses, is a leading cause of acute respiratory failure and multiple organ dysfunctions (Dushianthan et al., 2011). In experimental models, ALI can be triggered by either infectious or noninfectious stimuli, such as lipopolysaccharide (LPS) (Favarin et al.,
2013). Exposure to LPS, either by inhalation or via systemic administration (intravenous and intraperitoneal) elicits major features of microvascular lung injury, including leukocyte accumulation in the lung tissue, pulmonary edema, profound lung inflammation, and mortality (Gao et al., 2004; Shen et al., 2009). Current treatment of ALI/ARDS is primarily supportive, with lung protective ventilation and fluid conserving strategies (Cepkova and 
Matthay, 2006). Despite the improvement in these strategies, recent data indicate that the mortality of ALI/ARDS is still as high as 30 to 50\% (Rubenfeld et al., 2005; Diaz et al., 2010). Thus, there is a need for innovative therapies to further improve clinical outcomes of ALI/ARDS.

Mesenchymal stem cells (MSCs) are cells of stromal origin that can be isolated from multiple human tissues, such as bone marrow (BM), adipose tissue, skeletal muscle, synovium, gingiva, amniotic fluid, umbilical cord blood, and the umbilical cord (UC). The ability of MSCs to modulate the functions of cells associated with both innate and adaptive immune systems makes them promising therapeutic candidates in the treatment to various inflammatory diseases, including ALI/ARDS (Weiss and Sueblinvong, 2009).

The use of sodium bicarbonate for the treatment of severe lactic acidosis continues to generate intense debate (Gehlbach and Schmidt, 2004). Bicarbonate therapy is still used when intensive care practitioners are faced with patients whose $\mathrm{pH}$ falls below 7.20. In spite of this debate, a recent North American survey has shown that over twothirds of practitioners use this treatment when they faced patients with $\mathrm{pH}$ below 7.00 (Kraut and Kurtz, 2006).

\section{Materials and Methods}

\section{Animals}

Male albino rats weighing (150-200) gm were used in the present study. Animals were obtained from the breeding colony maintained at the animal house of the National Organization for Drug Control and Research (NODCAR, Cairo, Egypt). Animals were housed for at least one week in the laboratory room prior to testing under standard housing conditions (room temperature $25-27^{\circ} \mathrm{C}$ ) with alternating $12 \mathrm{hr}$ light and dark cycles. Free access to food (standard pellet diet) and water were allowed ad libitum unless otherwise specified. The standard guidelines of NODCAR were used in handling the experimental animals; these guidelines that complies with the Guide for Care and Use of Laboratory Animals published by the US National Institutes of Health (Marsch and Studer, 1999).

\section{Isolation of BM-MSCs}

Bone marrow was harvested by flushing the tibiae and femurs of 6 weeks old male white albino rats with Dulbecco's modified Eagle's medium (DMEM,GIBCO/BRL, Life Technologies, Grand Island, NY, USA) supplemented with $10 \%$ fetal bovine medium (GIBCO/BRL). Nucleated cells were isolated with a density gradient [Ficoll/Paque Pharmacia Biotech, Uppsala, Sweden] and resuspended in complete culture medium supplemented with $1 \%$ penicillin-streptomycin (GIBCO/BRL).Cells were incubated at $37^{\circ} \mathrm{C}$ in 5\% humidified $\mathrm{Co}_{2}$ for $12-14$ days as primary culture or upon formation of large colonies. When large colonies developed (80$90 \%$ confluence), cultures were washed twice with phosphate buffer saline (PBS) and cells were trypsinized with $0.25 \%$ trypsin in $1 \mathrm{mM}$ EDTA (GIBCO/BRL) for 5 minutes at $37^{\circ} \mathrm{C}$. After centrifugation $(2400 \mathrm{rpm}$ for 20 minutes), cells were resuspended with serumsupplemented medium and incubated in 50 $\mathrm{cm}^{2}$ culture flask (Falcon). The resulting cultures were referred to as first-passage cultures. On day 14, the adherent colonies of cells were trypsinized, and counted (Alhadlaq and Mao, 2004).

\section{Experimental design}

Rats were randomly allocated into five experimental groups; the first group served as control. The second group received 


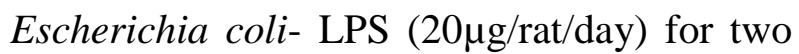
consecutive days intranasal (Wagner et al., 2003) with modification. The third group received $\left(1 \times 10^{6}\right)$ bone marrow derived mesenchymal stem cells in $500 \mu \mathrm{l}$ PBS/rat via intraperitoneal injection (Maron-Gutierrez et al., 2011). The fourth group received Dex (2mg/kg, i.p; Amriya Pharm, Egypt) once (Lin et al., 2006; Lv, 2016). The last group received Sodium bicarbonate $\left(\mathrm{NaHCO}_{3}\right)$ (200 mmol/L; 1.7\%) was provided with drinking water (each animal receives about $10-15 \mathrm{ml} /$ day for two consecutive days (Robey et al., 2009) with modification. All treated groups received LPS after 30 minutes from beginning treatment $(20 \mu \mathrm{g} / \mathrm{rat} / \mathrm{day})$ for two consecutive days in each nostril.

At the end of the experiment, 24 hours after last manipulation, the animals were weighted, respiratory rate/min was recorded followed by:

\section{Hematological parameters}

Clear serum separated for estimating the Creactive protein titer. $0.25-\mathrm{ml}$ blood sample was added to $20 \mathrm{mg}$ EDTA to be used for hematological investigations that included blood total leucocyte count and neutrophils percentage values.

\section{Physiological parameters}

\section{Respiratory rate}

Animals were allowed to adapt to the new environment for at least 5 minutes. Subsequently recordings were performed for a minimum of 5 minutes (Zehendner et al., 2013). Simple inspection of the respiratory cycle, observing rate and rhythm. The rate is noted by observing the frequency of the inspiratory phase, since this phase is active and easy to count. Recording the number of breaths per minute (BPM); this is the respiratory rate. While observing the rate, noting the inspiratory expansion of the chest cage (Braun, 1990).

\section{Relative lung weight}

The body and the isolated right lobe weights were estimated to measure the relative lung weight of each rat that were recorded according to the following formula (Uddin et al., 2014):

Relative lung weight $=\frac{\text { Organ weight }}{\text { Body weight }}$

\section{Blood pH}

Determination of Blood $\mathrm{pH}$ of freshly separated serum samples was recorded using $\mathrm{pH}$ strips in the range 6.4-8 [Merck's Reagenzien (Farbskala, zum); E. Merck A.G. Darmstadt, special-Indicator paper Merck pH 6.4-8] (Germany).

\section{Preparation of lung homogenate}

The right middle lung lobes were homogenized in ice-cold PBS (1:10 w/v). Homogenates were centrifuged at $4000 \mathrm{rpm}$ at $4^{\circ} \mathrm{C}$ for $15 \mathrm{~min}$ and supernatants were collected and stored at $-80^{\circ} \mathrm{C}$ until used for determination of malondialdehyde (MDA), reduced glutathione (GSH), and nitric oxide (NO) content.

\section{Oxidative stress biomarkers in lung tissue}

Lung contents of malondialdehyde (MDA) and reduced glutathione (GSH) were performed according to manufacturer's prescripts using reagent kits (Biodiagnostic Company, Cairo, Egypt). Total tissue nitrite/ nitrate (NOx) content was estimated according to method described by Montgomery and Dymock (1961). 
Quantitative RT-PCR for mucin rMuc-5AC gene expression in lung tissue

Quantitative RT-PCR is used to determine steady-state mucin gene (rMuc-5AC) mRNA levels in respiratory epithelum. Muc5AC is a specific protein for secretory mucin glycoproteins that is expressed in secretory epithelial cells and not in other cells of the airway. Photochemical pollution, and unique inflammatory biogenic substances such as allergens or bacterial endotoxin, results in augmented epithelial and inflammatory responses in rat nasal airways (Fanucchi et al., 1998; Wagner et al., 2002a).

Total RNA was isolated from dissected, homogenized axial airways using Qiagen tissue extraction kit (Qiagen, USA). RNeasy spin column was placed in a $1.5 \mathrm{ml}$ collection tube. $50 \mu \mathrm{l}$ RNase-free water was added directly to the spin column membrane, and centrifuged for $1 \mathrm{~min}$ at $\geq 8000 \mathrm{rpm}$ to elute the RNA. The purity (A260/A280 ratio) and the concentration of RNA were obtained using spectrophotometry (dual wavelength Beckman, Spectrophotometer, USA).The elute was transferred to a new Eppendorf tube and stored at $-80{ }^{\circ} \mathrm{C}$ for further use (Conaty et al., 2006; Lopez and Bohuski, 2007).

\section{cDNA synthesis}

The total RNA $(1 \mu \mathrm{g})$ was used for cDNA conversion using high capacity cDNA reverse transcription kit Fermentas, USA). Three $\mu$ of random primers were added to total RNA which was denatured for 5 minutes at $65^{\circ} \mathrm{C}$ in the thermal cycler. The RNA primer mixture was cooled to $4^{\circ} \mathrm{C}$ and the cDNA master mix was prepared according to the kit instructions and was added (for each sample). Total volume of the master mix was $19 \mu \mathrm{l}$ for each sample. This was added to the $31 \mu \mathrm{RNA}$ primer mixture resulting in $50 \mu \mathrm{l}$ of cDNA. The last mixture was incubated in the programmed thermal cycler one hour at $37^{\circ} \mathrm{C}$ followed by inactivation of enzymes at $95^{\circ} \mathrm{C}$ for 10 minutes, and finally cooled at $4^{\circ} \mathrm{C}$. Then RNA was changed into cDNA. The converted cDNA was stored at $-20{ }^{\circ} \mathrm{C}$.

\section{Real-time qPCR using SYBR Green I}

Real-time qPCR amplification and analysis were performed using an Applied Biosystem with software version 3.1 (StepOne ${ }^{\mathrm{TM}}$, USA). The qPCR assay with the primer sets (Guzman et al., 1996) were optimized at the annealing temperature. The primer sequence was MUC5ac Forward primer: 5'- GCC CTC CGG ACA GAA GCA GCC TTC-3'; Reverse primer: 5'- GGC CAG TGC GGC ACT TGC ACC AAC-3'. For each sample the following reagents and volumes were added: Forward Primer $(1 \mu \mathrm{l})$, Reverse Primer $(1 \mu \mathrm{l})$, Syber green mix $(12.5 \mu \mathrm{l})$, cDNA template $(5 \mu \mathrm{l})$ and RNAse free water $(5.5 \mu \mathrm{l})$ with total volume 25 $\mu 1$. Taq DNA polymerase (0.62 units) was added to the cDNA samples, for a final volume of $25 \mu 1$ (Taq polymerase was added to the PCR master-mix with the following thermal cycling conditions: One cycle Hold stage at $50^{\circ} \mathrm{C}$ for $2: 00$ mins., 40 cycles of Denaturation at $95^{\circ} \mathrm{C}$ for $0: 15 \mathrm{sec}$, Annealing at $60^{\circ} \mathrm{C}$ for $1: 00 \mathrm{~min}$ and Extension at $72^{\circ} \mathrm{C}$ for 1:00 min. The relative quantitation was calculated according to Applied Biosystem software using the following equation;

$\Delta \mathrm{Ct}=\mathrm{Ct}$ gene test $-\mathrm{Ct}$ endogenous control $\Delta \Delta \mathrm{Ct}=\Delta \mathrm{Ct}$ sample $1-\Delta \mathrm{Ct}$ calibrator $\mathrm{RQ}=$ Relative quantification $=2-\Delta \Delta \mathrm{Ct}$

The RQ is the fold change compared to the calibrator (untreated sample).

\section{Histopathological examination}

At the end of the experiments, lower lobe were taken from the right lung of rats in the different experimental groups, collected on 
glass slides, deparaffinized and stained with hematoxylene and eosin stain for routine examination through the light electricmicroscope (Bancroft et al., 1996).

\section{Immunohistochemistry marker caspase 3}

Lung sections were deparaffinized and rehydrated through xylene and alcohol for assessment of Caspase-3. Antigen unmasking was performed by incubating the sections for 20 min in citrate buffer (Thermo Fisher Scientific, Fremont, CA; pH 6.0) at the boiling point then cooled and incubated overnight at 4 ${ }^{\circ} \mathrm{C}$ with the rabbit polyclonal anti-Caspase-3 (1:200; Thermo Fisher Scientific) primary antibody.

After washing with PBS, the slides were incubated for $30 \mathrm{~min}$ at $37{ }^{\circ} \mathrm{C}$ with the biotinylated secondary antibody then with the Vector Elite ABC kit (Elite reagent Avidin $\mathrm{DH}$ and biotinylated horseradish peroxidase $\mathrm{H}$ reagents; Vector Laboratories Inc., Burlingame, CA). After another wash with PBS, the antibody-biotin-avidin-peroxidase complex was developed using diaminobenzidine tetrahydrochloride (DAB Substrate Kit, Vector Laboratories Inc.).

Sections were counterstained with hematoxylin, dehydrated, and cleared in xylene then coverslipped, where the reaction appeared as a brown cytoplasmic reaction (ElGarhy et al., 2014).

\section{Statistical analysis}

Statistical significance of differences between means of groups was performed using the Prism computer program (GraphPad software Inc. V5, San Diego, CA). One-way analysis of variance (ANOVA) was employed to calculate the statistical significance followed by TukeyKramer multiple comparison test. A value of $P<0.05$ was considered significant.

\section{Results and Discussion}

\section{Respiratory rate}

The present study showed that LPS treated group increased respiratory rate (rate/min.) when compared with control group. Meanwhile, all treated groups resulted in a significant reduction in the respiratory rate (rate/min.) in comparison with LPS treated group (Table 1). According to Hagawane et al., (2016), LPS produced a refractory hypoxaemia that persisted for at least $30 \mathrm{~h}$. resulting in tachypnoea, elevated total protein concentration in the BALF, destruction of alveolar structure and infiltration of pulmonary tissue by large number of inflammatory cells (primarily neutrophils). This method induced temporary hypoxaemia that mimicked ALI, Li and Wei (2009) showed that LPS two hit induced refractory hypoxaemia ARDS rat model associated with prolonged hypoxaemia and specific pulmonary injury in rats.

\section{Relative lung weight $\%$}

Relative lung weight (RLW) was assessed to give an indication about the edema degree. As shown in table 1, ALI induced by LPS injection resulted in a significant increase in relative lung weight as compared with control group.

Treatment with BM-MSCs and intraperitoneal administration of dexamethasone were accompanied by normalization of relative lung weight as compared with LPS group. Whereas administration of sodium bicarbonate in rats recorded a significantly reduced relative lung weight when compared with endotoxin group. According to Fikry et al., (2015) they showed that rats treated with MSCs exhibited normal weight gain as compared to methotrexate (MTX) group. This was directly reflected by a significant decrease in relative lung weights. 
Zhao et al., (2014) found that levels of phosphoinositide-3-kinase/Akt (p-Akt) protein expression in lung tissue significantly decreased, with a large amount of protein leakage and the release of inflammatory cytokines, and an increase in water content in the lung in LPS-induced ALI. Besides, pulmonary oedema induced by LPS was markedly enhanced by Metallothionein (MT) deficiency. As for lung inflammation, inhaled LPS induces MT expression in vivo (Hur et al., 1999) which suggests that MT may play a role in lung inflammation induced by LPS. MT is a protein that can be induced by inflammatory mediators and participate in cytoprotection through transcriptional regulatory factors, proinflammatory molecules and nuclear factor- $\kappa \mathrm{B}(\mathrm{NF}-\kappa \mathrm{B})$ activation and the subsequent expression of proinflammatory mediators. Based on previous reports Hur et al., (1999) suggested that MT may have protective properties against acute inflammatory lung injury induced by bacterial endotoxin. LPS treatment increased COX-2 and Rho kinase proteins in the lung (Falk et al., 1999). On the other hand, the immunomodulatory and therapeutic effects of MSCs for ALI and sepsis played a role in the regulation of inflammatory cascade in LPS challenged lung lung (Ho et al., 2015).

\section{Total leukocyte count and neutrophil percent in the blood}

The present study showed that LPS treated group showed significantly increased the total leucocytes count and neutrophilic efflux when compared with control group. Meanwhile, MSCs treatment, administration of dexamethasone and treatment with sodium bicarbonate $\left(\mathrm{NaHCO}_{3}\right)$ reduced the total leucocytes count when compared with infected group (Figure 1).

In agreement with our results, Hagawane et al., (2016) showed that intratracheal instillation of LPS resulted in tachypnoea, elevated total protein concentration in the BALF, destruction of alveolar structure and infiltration of pulmonary tissue by large number of inflammatory cells (primarily neutrophils).

$\mathrm{Xu}$ et al., (2007) injected C57BL/6 mice intraperitoneally with endotoxin followed by intravenous infusion of MSCs prevented endotoxin-induced lung inflammation, injury, and edema. It also suppressed the endotoxininduced increase in circulating proinflammatory cytokines, including IFN- $\gamma$, IL$1 \beta$, MIP1- $\alpha$, and KC (murine homolog of IL8 ), without decreasing circulating levels of anti-inflammatory mediators. The current data is also consistent with the findings of Rojas et al., (2014).

Huang et al., (2014) showed that early low dose of dexamethasone treatment has a protective effect on oleic acid (OA) induced ALI which reduced respiratory rate, decreased lung index, suppressed the production of inflammatory cytokines, reduced accumulation and activation of pulmonary neutrophils, and prevent from lung injury which consolidates our findings.

\section{Blood pH value}

The results displayed that rats challenged with LPS induced respiratory acidosis as blood $\mathrm{pH}$ was reduced when compared with control group. Whereas treatment with BM-MSCs, intraperitoneal administration of dexamethasone and administration of sodium bicarbonate in rats significantly increased the blood $\mathrm{pH}$ when compared with LPS group (Table 2).

Kim et al., (2012) demonstrated that when inflammatory mediator like endotoxin LPS was injected directly into the airway, it developed inflammatory pulmonary edema in 
the lung, and could induce respiratory distress syndrome. It induced respiratory acidosis as well reducing the blood $\mathrm{pH}$.

Meanwhile the antioxidants, taurine and dexamethasone turned the blood $\mathrm{pH}$ to the normal condition, increased blood hemoglobin and hemocrit concentration and oxygen partial pressure (PO2), and could increase the survival rate (Jeon et al., 2009).

Boyd and Walley (2008) displayed that sodium bicarbonate in doses of $1-2 \mathrm{mEq} / \mathrm{kg}$ significantly raise the $\mathrm{pH}$ and serum bicarbonate as well as the partial pressure of carbon dioxide, although this effect is transient. This does not translate into improved hemodynamics or augmented sensitivity to catecholamines, possibly due to a decrease in serum ionized calcium levels.

\section{Oxidative stress biomarkers in lung tissue}

As shown in figure 2, LPS administration induced a significant elevation in lung lipid peroxides represented as MDA ( $\mathrm{nmol} / \mathrm{g})$, nitric oxide level $(\mu \mathrm{mol} / \mathrm{g})$, along with marked decrease in lung GSH content $(\mu \mathrm{mol} / \mathrm{g})$ as compared to the control group. While treatment with BM-MSCs and dexamethasone antagonized these effects by a prominent mitigation of MDA content and decrement in the level of NO with reversed depletion of GSH level in lung tissues when compared with LPS treated group. Meanwhile, administration of $\mathrm{NaHCO}_{3}$ was not associated with any changes of MDA level when compared with LPS treated group, while depletion of both GSH and NO levels showed a reverse action to normal values when compared to LPS group.

Table.1 Effect of MSCs, Dex and $\mathrm{NaHCO}_{3}$ treatment on respiratory rate and lung weight of rats with LPS- induced ALI

\begin{tabular}{|c|c|c|}
\hline Animal group & $\begin{array}{c}\text { Respiratory rate } \\
\text { (rate/min.) }\end{array}$ & $\begin{array}{c}\text { Relative lung weight } \\
\%\end{array}$ \\
\hline Normal control (co) & $\mathbf{7 6 . 5 0 \pm 1 . 6 3}$ & $3.74 \pm 0.14$ \\
\hline LPS & $\mathbf{8 7 . 3 3} \pm \mathbf{2 . 1 7} *$ & $5.19 \pm 0.37 *$ \\
\hline LPS+MSCs & $\mathbf{7 4 . 6 7 \pm 1 . 3 3 +}$ & $3.44 \pm 0.26+$ \\
\hline LPS+Dex & $\mathbf{7 0 . 6 7} \pm \mathbf{2 . 4 5 +}$ & $4.17 \pm 0.12+$ \\
\hline LPS+NaHCO & $\mathbf{5 6 . 3 3 \pm 4 . 1 5 * + \#}$ & $4.64 \pm 0.18 \#$ \\
\hline
\end{tabular}

Table.2 Effect of MSCs, Dex and $\mathrm{NaHCO}_{3}$ treatment on blood $\mathrm{pH}$ value of rats with LPSinduced ALI

\begin{tabular}{|c|c|}
\hline Animal group & Blood pH value \\
\hline Normal control (co) & $7.40 \pm 0.0$ \\
\hline LPS & $6.98 \pm 0.06 *$ \\
\hline LPS+MSCs & $7.28 \pm 0.03+$ \\
\hline LPS+Dex & $7.35 \pm 0.02+$ \\
\hline LPS+NaHCO & $7.27 \pm 0.03+$ \\
\hline
\end{tabular}

Values are expressed as mean \pm SEM of 6-8 rats per group. *vs. control group, +vs. LPS group, \#vs. LPS+ MSCs group (one-way ANOVA followed by Tukey- Kramer multiple comparisons test; $p<0.05$ ). Where, BM-MSCs; bone marrow mesenchymal stem cells, LPS; lipopolysaccharide, Dex; dexamethasone, $\mathrm{NaHCO}_{3}$; sodium bicarbonate. 
Fig.1 Effects of BM-MSCs on total cell count \& neutrophils in peripheral blood as compared with dexamethasone and sodium bicarbonate in rats subjected to LPS- induced acute lung injury

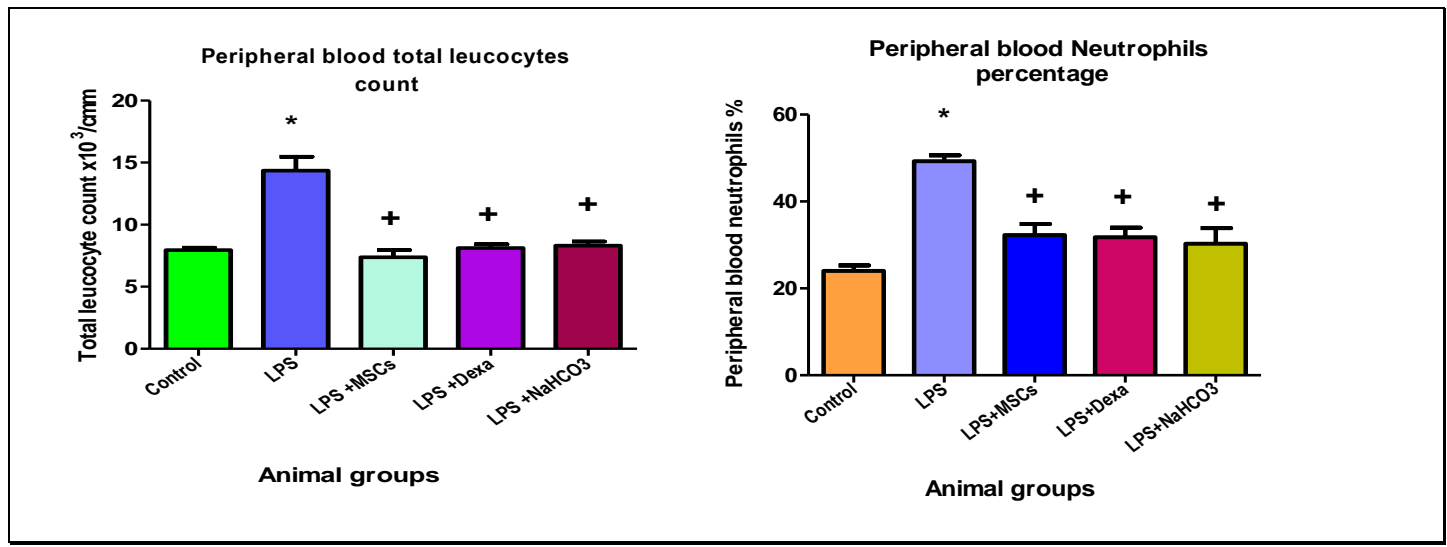

Values are expressed as mean \pm SEM of 6-8 rats per group. *vs. control group, +vs. LPS group, \#vs. LPS+ MSCs group (one-way ANOVA followed by Tukey- Kramer multiple comparisons test; $p<0.05$ ). Where, BM-MSCs; bone marrow mesenchymal stem cells, LPS; lipopolysaccharide, Dex; dexamethasone, $\mathrm{NaHCO}_{3}$; sodium bicarbonate.

Fig.2 Effects of BM-MSCs on oxidative stress biomarkers in lung tissue as compared with Dex and $\mathrm{NaHCO}_{3}$ in rats subjected to LPS (A) Malondialdehyde (MDA); (B) Glutathione (GSH) concentrations and $\mathrm{C}$ ) level of nitric oxide (NO)
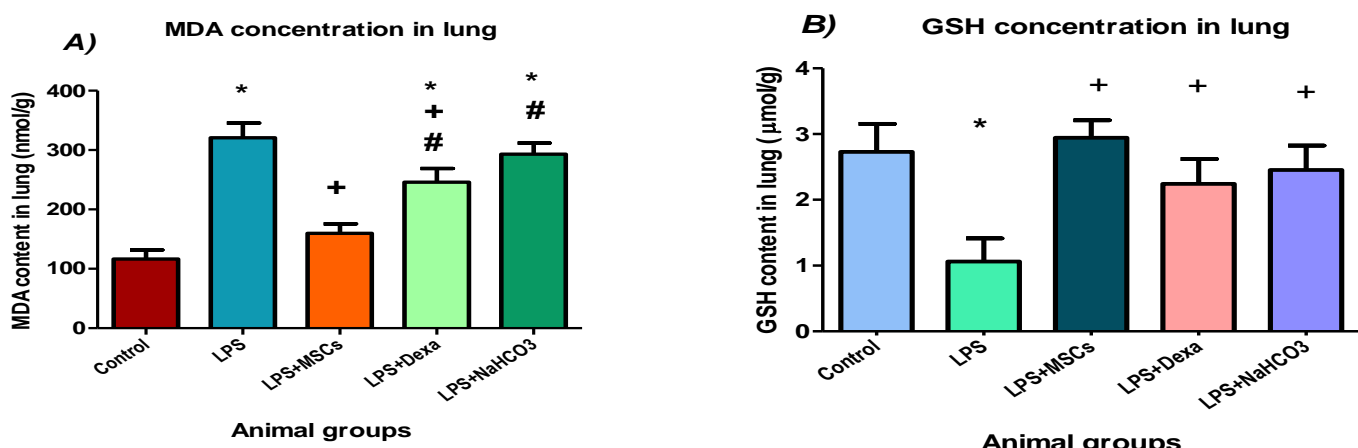

Animal groups

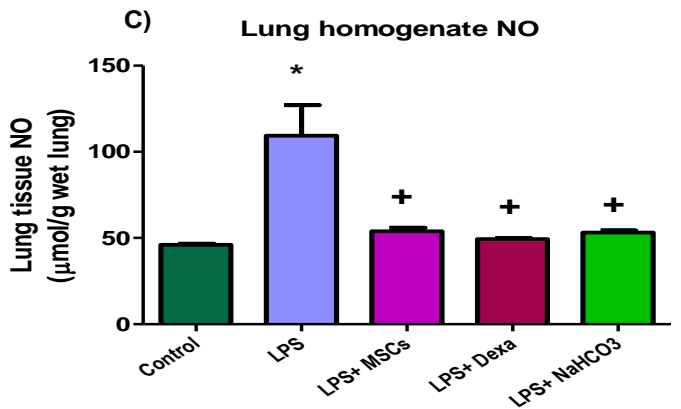

Animal groups

Values are expressed as mean \pm SEM of 6-8 rats per group. *vs. control group, +vs. LPS group, \#vs. LPS+ MSCs group (one-way ANOVA followed by Tukey- Kramer multiple comparisons test; $p<0.05$ ). Where, BM-MSCs; bone marrow mesenchymal stem cells, LPS; lipopolysaccharide, Dex; dexamethasone, $\mathrm{NaHCO}_{3}$; sodium bicarbonate. 
Fig.3 Effect of BM-MSCs on rMuc-5AC mRNA gene expression in lung tissue as compared with Dex and $\mathrm{NaHCO}_{3}$ in rats subjected to LPS.

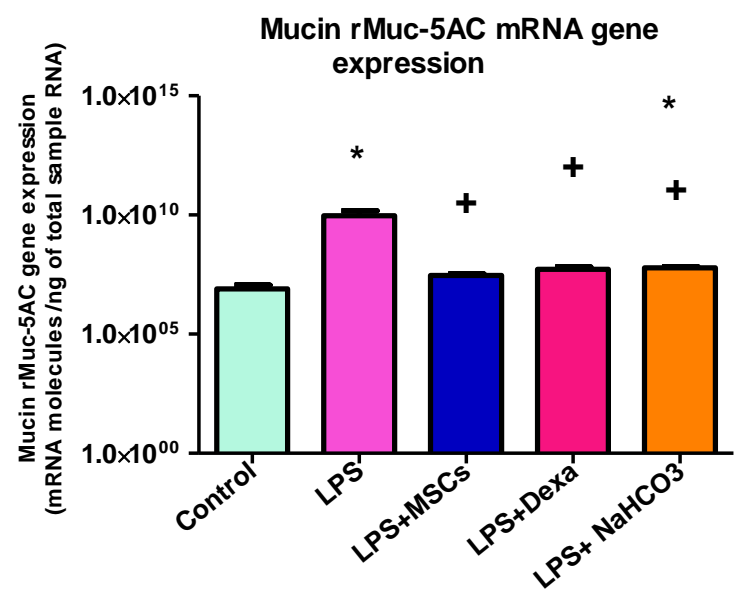

Animal groups

Values are expressed as mean \pm SEM of 6-8 rats per group. *vs. control group, +vs. LPS group, \#vs. LPS+ MSCs group (one-way ANOVA followed by Tukey- Kramer multiple comparisons test; $p<0.05$ ).Where, BM-MSCs; bone marrow mesenchymal stem cells, LPS; lipopolysaccharide, Dex; dexamethasone, $\mathrm{NaHCO}_{3}$; sodium bicarbonate.

Fig.4 Lung sections stained with hematoxylin and eosin of a) control animals showing the normal histological structure of lung b) LPS treated rat showing marked interstitial pneumonia, necrotic alveoli and congested blood vessels c) LPS-BM-MSCs group showing apparent normal pulmonary alveoli, associated with interstitial cellular infiltration d) Dexamethasone treated rats

in LPS induced ALI animal group is showing mild pneumonia and moderate alveolar and interstitial mononuclear inflammatory cells infiltration e) Sod. bicarbonate treated rats in LPS induced ALI animal group showing interstitial pneumonia (H \& E X 400)

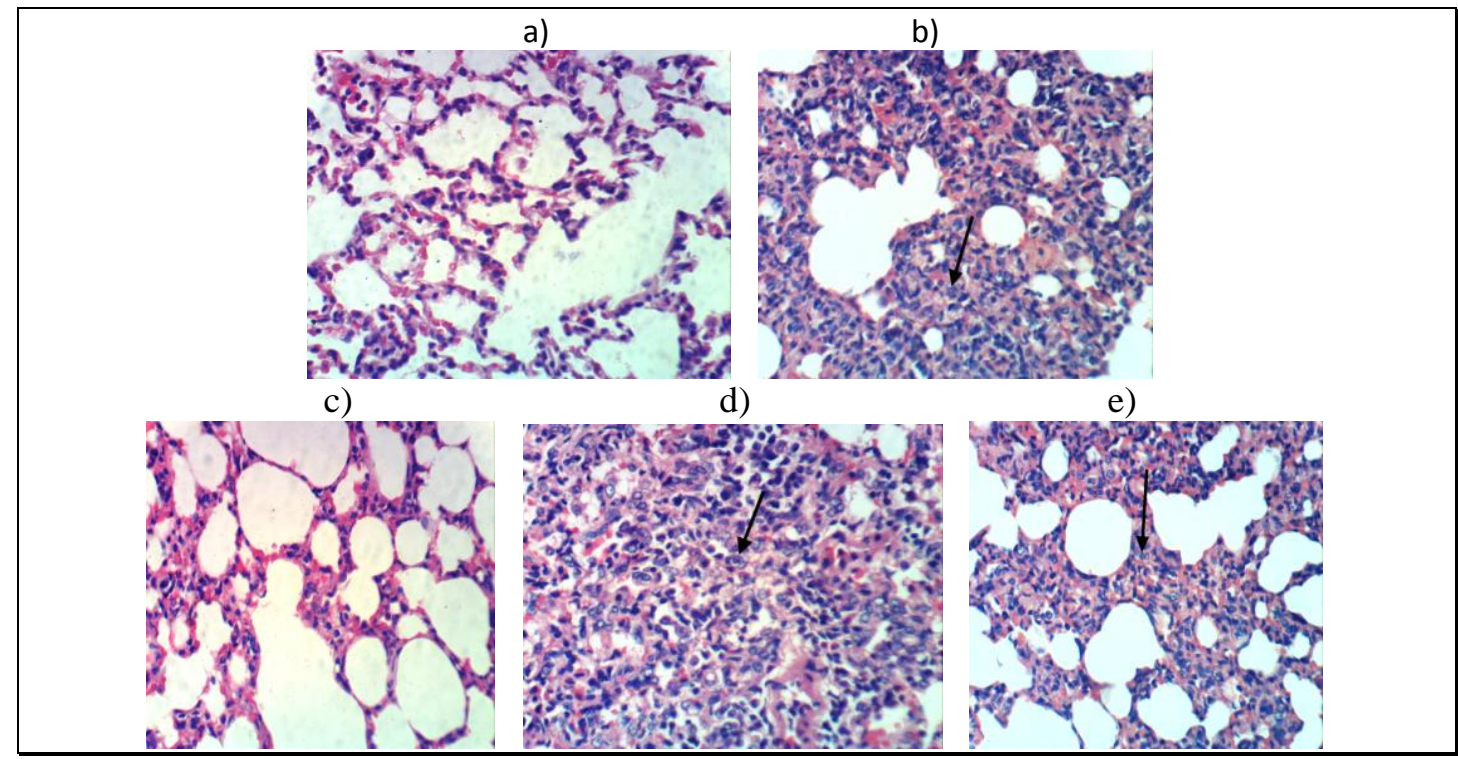


Fig.5 Immunohistochemical staining of Caspae 3 in lung Photomicrographs sections obtained from: (a) control rats (b) LPS induced ALI (c) BM-MSCs treated rats in LPS induced ALI (d)

Dexamethasone treated rats in LPS induced ALI (e) Sod.

bicarbonate treated rats in LPS induced ALI

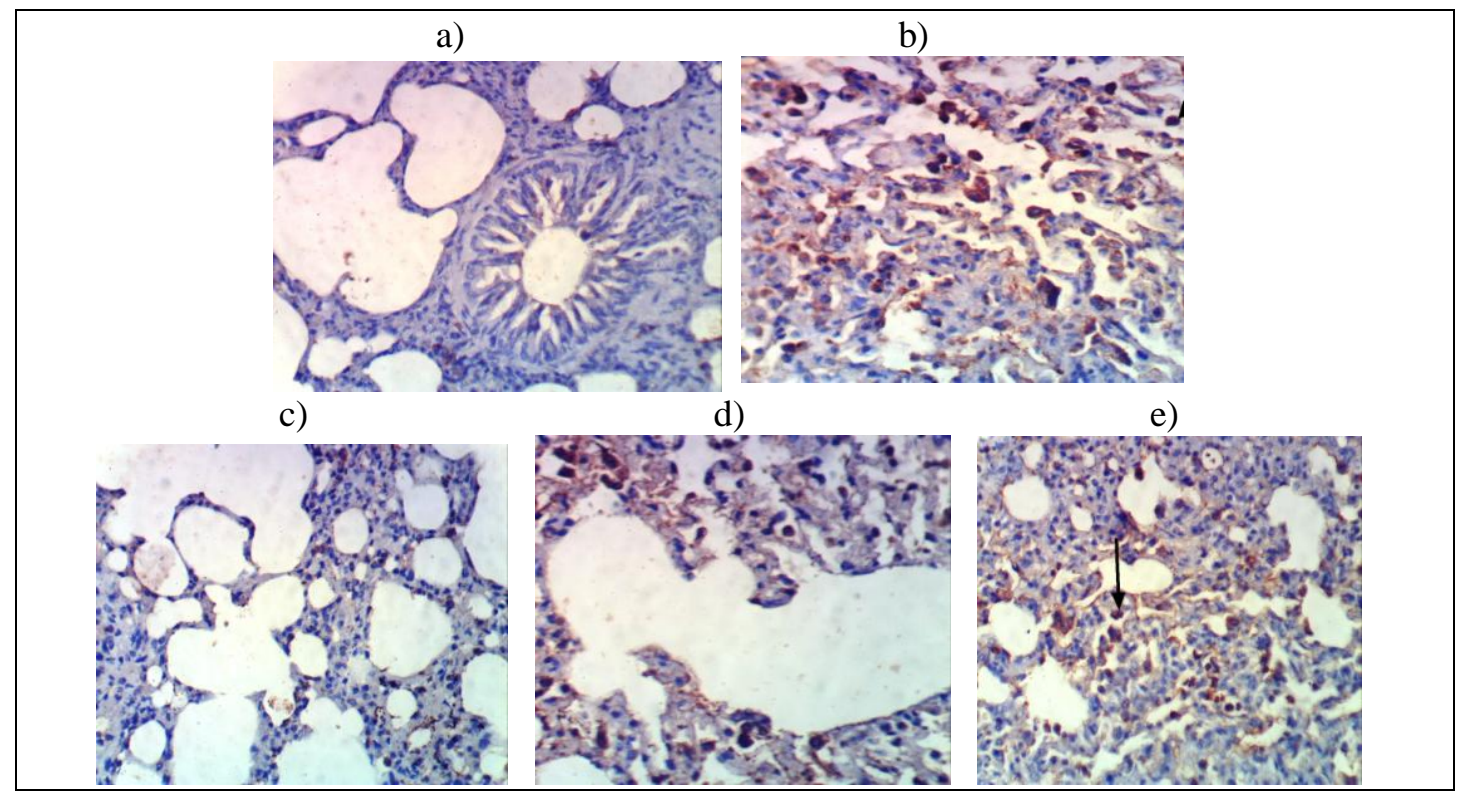

This data is in line with the finding of Shalaby et al., (2014) who reported an increased survival rate, reduced pulmonary edema and attenuated lung injuries in ALI mice through an increase of anti-oxidant enzyme activities and a decrease of myeloperoxidase activity and malondialdehyde levels in the MSC recipient groups versus the ALI group. These was accompanied by weak +ve inducible nitric oxide synthase immuno-expression in that groups received MSCs tratment.

A similar observations has been found by AlHarbi et al., (2016) who demonstrated the potent anti-inflammatory action of the DEX against acute lung injury induced by LPS. Treatment with DEX resulted in significant decrease in neutrophils and lymphocytes count as well as administration of DEX resulted in marked decrease in malondialdehyde (MDA) levels and myeloperoxidase (MPO) activity. Besides, Yu et al., (2009) demonstrated that dexamethasone attenuates endotoxin-induced lung injury through inhibiting production of NO in lung tissue.

\section{Mucin rMuc-5AC gene expression in lung tissue}

In the present study, the significant decrease of BALF PMNs in MSCs treated rats was associated with significant decrease in Muc5AC RNA expression. This finding agreed with Nejad-Moghaddam et al., (2016).

The current study revealed that ALI induced by LPS injection caused an increment in mRNA expression of rMuc-5AC as compared with control group. Whereas treatment with BM-MSCs, intraperitoneal administration of dexamethasone and administration of sodium bicarbonate in rats decline mRNA expression of rMuc-5AC significantly as compared with LPS group as shown in figure 3 . These results were in agreement with the findings of Lu et al., (2005) who demonstrated that dexamethasone suppressed both MUC5AC 
mRNA levels and MUC5AC protein secretion in a dose-dependent manner.

These changes were explained by Wagner et al., (2014) who demonstrated that LPS increased BALF total cells, neutrophils, protein, PGE2, and secreted mucins. Besides, neutrophils and IM were detected in conducting airways. Pulmonary expression of MUC5AC, MIP-2, CINC-1, and MCP-1 was elevated. Recruitment of PMNs into lung airspaces occurs in response to a variety of airway stimuli and involves the stepwise process of adhesion molecule expression on PMNs, epithelial cells, and endothelial cells in both the pulmonary capillaries and the bronchial venules. Reactive oxygen species (ROS) and elastase released from emigrated neutrophils are primary factors in the pathogenesis of neutrophil-mediated airway injury and disease (Grommes and Soehnlein, 2011).

Interventions to protect from oxidant-induced tissue injury mediated by PMNs include, among others, glucocorticosteroids in which Dexamethasone inhibits phagocyte nicotinamide adenine dinucleotide phosphate oxidase activity by down-regulating expression of genes encoding oxidase components (Condino-Neto et al., 1998). Antioxidants interact directly with and neutralize ROS which have been used to reverse oxidant-mediated pulmonary injury. Protection from endotoxin-induced inflammation may be mediated by the inhibition of atypical protein kinase $\mathrm{C}$ (aPKC) which is an enzyme critical to NF- $\kappa \mathrm{B}$ activation by LPS in macrophages (Huang et al., 2009). Therefore, it is expected that MSCs reduce MUC5AC production through an antioxidant mechanisms.

Bicarbonate is required for proper mucin secretion (Gustafsson et al., 2012). According to Quinton (2010), IL-1beta may be an important defense mechanism of the airway epithelium to enhance mucociliary clearance during airway inflammation. IL-1beta increased the secretion of MUC5AC, but not MUC5B. The changes in the level of MUC5AC where directly affected by $\mathrm{pH} /\left[\mathrm{HCO}_{(3)}(-)\right.$ of the airway surface (Gray et al., 2004). Data are showing that $\mathrm{HCO}_{3}(-)$ is required for normal mucus discharge, $\mathrm{HCO}_{(3)}(-)$ may support mucus discharge therefore the failure to transport this electrolyte is pathogenic.

\section{Histological examination}

As shown in figure 4, lung tissues stained with hematoxylin and eosin in the control group revealed normal histological structure (Fig. 4a). The microscopic appearance of lung tissues stained with hematoxylin and eosin in rats infected with LPS showed marked interstitial pneumonia. Note massive interstitial mononuclear cells infiltration, thickening of the alveolar capillary membrane, lung septae were obviously thickened, shedding and sloughing of bronchiolar epithelium, edema as well as extensive interstitial and alveolar infiltration with neutrophils and peribronchial inflammatory cells aggregation (Fig. 4b).

Histopathological sections obtained from animals administered bone marrow- derived mesenchymal stem cells (BM-MSCs) (1ml/animal, i.p.) displayed signs of lung recovery with reduced severity of lung injury where the main inflammatory cells, particularly macrophages and a few neutrophils, were scattered among the wall of the bronchioles and the alveolar cells. MSCs restored alveolar epithelial cells to their normal structure (Fig. 4c).

Section of LPS lung injured animals treated with dexamethasone showed a significant improvement of interstitial edema, 
hemorrhage, infiltration of inflammatory PMNs and leucocytes. Also, lung sections showed a marked improvement of interstitial pneumonia, reduced alveolar wall thickening with emphysematous appearance (Fig. 4d).

Meanwhile, lung sections of LPS induced lung injury in rats treated with Sod. bicarbonate showed moderate interstitial pneumonia, edema and macrophages infiltration (Fig. 4e).

\section{Immunohistochemistry marker caspase 3}

Caspase 3 immunohistochemical staining of lungs obtained from control rats revealed very few caspase 3 positive cells in the alveolar septa (Fig. 5a). Caspase 3 immunohistochemical staining in lung sections of rats treated with LPS showed strong positive expression of Caspase 3 where immunopositivity is indicated by brown colour (Fig. 5b).

Immunohistochemical staining of Caspae 3 in lung of LPS induced ALI rat model treated with BM-MSCs showed weak positive expression of Caspase 3 (Fig. 5c), indicating that treatment could protect lung alveolar epithelial cells from apoptotic injury.

Meanwhile immunohistochemical staining of Caspae 3 in lung of LPS induced ALI rat model treated with dexamethasone and sodium bicarbonate showed moderate positive expression of Caspase 3 (Fig. 5d\&e) respectively.

In conclusion, the present study suggests that bone marrow-derived MSCs can limit experimentally-induced lung injury and protect the lung tissues. This protection is multifactorial including modulating the oxidative stress reaction, tissue damage and protects the alveolar capillary barrier function comparison with other drugs.

\section{Acknowledgment}

The authors are grateful to Dr. Kawkab Abdel-Aziz, Professor of Pathology, Faculty of Veterinary Medicine, Cairo University, for her helpful guide in histopathological and immunohistochemical examination and $\mathrm{Dr}$ Lila Rashid, Faculty of Medicine, Cairo University for her helpful guide in Molecular biology Assays.

\section{References}

Alhadlaq, A. and Mao, J.J. 2004. Mesenchymal stem cells: isolation and therapeutics. Stem Cells Dev., 13(4): 436-448.

Al-Harbi, N.O., Imam, F., Al-Harbi, M.M., Ansari, M.A., Zoheir, K.M., Korashy, H.M., Sayed-Ahmed, M.M., Attia, S.M., Shabanah, O.A. and Ahmad, S.F. 2016. Dexamethasone attenuates LPS-induced acute lung injury through inhibition of $\mathrm{NF}-\kappa \mathrm{B}, \mathrm{COX}-2$, and pro-inflammatory mediators. Immunol. Invest., 45(4):349369.

Bancroft, J.D., Stevens, A. and Turner, D.R. 1996. Theory and practice of histological techniques (4th edition). pp. 99-112, U.K. Churchill Livingston.

Boyd, J.H. and Walley, K.R. (2008): Is there a role for sodium bicarbonate in treating lactic acidosis from shock? Curr. Opin. Critical Care, 14(4): 379-383.

Braun, S.R. 1990. Clinical Methods: The history, physical, and laboratory examinations. Chapter 43. Respiratory Rate and Pattern, 3rd edition. Boston. pp.226.

Cepkova, M. and Matthay, M.A. 2006. Pharmacotherapy of acute lung injury and the acute respiratory distress syndrome. $J$. Intensive Care Med., 21(3):119-143.

Conaty, J., Bogart, K. and Andrews, J. 2006. Direct labeling and hybridization protocol. CGB technical report 2006-09. The center for genomics and bioinformatics, Indiana University, Bloomington. 
Condino-Neto, A., Whitney, C. and Newburger, P.E. 1998. Dexamethasone but not indomethacin inhibits human phagocyte nicotinamide adenine dinucleotide phosphate oxidase activity by downregulating expression of genes encoding oxidase components. J. Immunol., 161(9):4960-4967.

Diaz, J.V., Brower, R., Calfee, C.S., Matthay MA: Therapeutic strategies for severe acute lung injury. Crit. Care Med., 2010, 38:1644-1650.

Dushianthan, A., Grocott, M.P., Postle, A.D. and Cusack, R. 2011. Acute respiratory distress syndrome and acute lung injury. Postgrad. Med. J., 87:612-622.

El-Garhy, A.M., Abd El-Raouf, O.M., ElSayeh, B.M., Fawzy, H.M. and Abdallah, D.M. 2014. Ellagic acid antiinflammatory and antiapoptotic potential mediate renoprotection in cisplatin nephrotoxic rats. J. Biochem. Mol. Toxicol., 28 (10):472-479.

Falk, S., Goggel, R., Heydasch, U., Brasch, F., Muller, K.M., Wendel, A. and Uhlig, S. 1999. Quinolines attenuate PAF-induced pulmonary pressor responses and edema formation. Am. J. Respir. Crit. Care Med.,160 (5Pt 1):1734-1742.

Fanucchi, M.V., Hotchkiss, J. A. and Harkema, J. R. 1998. Endotoxin potentiates ozoneinduced mucous cell metaplasia in rat nasal epithelium. Toxicol. Appl. Pharmacol., 152(1): 1-9.

Favarin, D.C., de Oliveira, J.R., de Oliveira, C.J. and Rogerio, A.P. 2013. Potential effects of medicinal plants and secondary metabolites on acute lung injury. Biomed. Res. Int., 2013: 576479.

Fikry, E.M., Safar, M.M., Hasan, W.A., Fawzy, H.M. and El-Denshary, E.E. 2015. Bone Marrow and adipose-derived mesenchymal stem cells alleviate methotrexate-induced pulmonary fibrosis in rat: comparison with dexamethasone. $J$. Biochem. Mol. Toxicol., 29(7):321-9.

Gao, J., Zeng, B.X., Zhou, L.J. and Yuan, S.Y. 2004. Protective effects of early treatment with propofol on endotoxin-induced acute lung injury in rats. Br. J. Anaesth., 92(2): 277-279.

Gehlbach, B.K. and Schmidt, G.A. 2004. Bench-to-bedside review: treating acid base abnormalities in the intensive care unit: the role of buffers. Crit. Care, 8:259-265.

Gray, T., Coakley, R., Hirsh, A., Thornton, D., Kirkham, S., Koo, J.S., Burch, L., Boucher, R. and Nettesheim, P. 2004. Regulation of MUC5AC mucin secretion and airway surface liquid metabolism by IL-1beta in human bronchial epithelia. Am. J. Physiol. Lung Cell. Mol. Physiol., 286(2):L320-30.

Grommes, J. and Soehnlein, O. 2011. Contribution of neutrophils to acute lung injury. Mol. Med., 17(3-4):293-307.

Gustafsson, J.K., Ermund, A., Ambort, D. Johansson, M.E., Nilsson, H.E., Thorell, K., Hebert, H., Sjovall, H. and Hansson, G.C. 2012. Bicarbonate and functional CFTR channel are required for proper mucin secretion and link cystic fibrosis with its mucus phenotype. J. Exp. Med., 209 (7):1263-72.

Guzman, K., Bader, T. and Nettesheim, P. 1996. Regulation of MUC5 and MUC1 gene expression: correlation with airway mucus differentiation. Am. J. Physiol. 270 (5 Pt 1): L846-L853.

Hagawane, T.N., Gaikwad, R.V. and Kshirsagar, N.A. 2016. Dual hit lipopolysaccharide and oleic acid combination induced rat model of acute lung injury/acute respiratory distress syndrome. Indian J. Med. Res., 143 (5): 624-632.

Ho, M.S., Mei, S.H. and Stewart, D.J. 2015. The immunomodulatory and therapeutic effects of mesenchymal stromal cells for acute lung injury and sepsis. J. Cell. Physiol., 230(11):2606-17.

Huang, B., Wang, D.X. and Deng, W. 2014. Protective effects of dexamethasone on early acute lung injury induced by oleic acid in rats. Int. J. Clin. Exp. Med., 7(12):4698-709. 
Huang, X., Chen, L.Y., Doerner, A.M., Pan, W.W., Smith, L., Huang, S., Papadimos, T.J. and Pan, Z.K. 2009. An atypical protein kinase $\mathrm{C}$ (PKC zeta) plays a critical role in lipopolysaccharideactivated NF-kappa B in human peripheral blood monocytes and macrophages. J. Immunol., 182(9):58105.

Hur, T., Squibb, K., Cosma, G., Horowitz, S., Piedboeuf, B., Bowser, D. and Gordon, T. 1999. Induction of metallothionein and heme oxygenase in rats after inhalation of endotoxin. J. Toxicol. Environ. Health A, 56 (3):183-203.

Jeon, S.H., Lee, M.Y., Rahman, M.M., Kim, S.J., Kim, G.B., Park, S.Y., Hong, C.U., Kim, S.Z., Kim, J.S. and Kang, H.S. 2009. The antioxidant taurine reduced lipopolysaccharide (LPS)-induced generation of ROS, and activation of MAPKs and Bax in cultured pneumocytes. Pulm. Pharmacol. Ther., 22(6):562-566.

Kim, S.J., Kim, K.H., Kim, S.J., Kang, H.S., Kim, J.S., Kim, M.H., Jo, J.K., Choi, J.B., Yang, Y.S., Kang, S.J. and Kim, G.B. 2012. Effectiveness of antioxidant and membrane oxygenator in acute respiratory distress syndrome by endotoxin. Korean J. Chem. Eng., 29(11): 1597-1603.

Kraut, J.A. and Kurtz, I. 2006. Use of base in the treatment of acute severe organic acidosis by nephrologists and critical care physicians: results of an online survey. Clin. Exp. Nephrol., 10:111-117.

Li, Y. and Wei, H. 2009. Lipopolysaccharide "two-hit" induced refractory hypoxemia acute respiratory distress model in rats. $J$. Huazhong Univ. Sci. Technolog. Med. Sci., 29(4):470-475

Lin, Q., Wang, G.F., Tang, X.Y. and Zou, S.L. 2006. Effects of dexamethasone on acute lung injury in rats induced by lipopolysacharide. J. Peking University (Health sciences), 38 (4): 393-396.

Lopez, J. A. and Bohuski, E. 2007. Protocol: Total RNA extraction with TRIZOL reagent and purification with QIAGEN RNeasy mini kit. Indiana University.

Lu, W., Lillehoj, E.P. and Kim, K.C. 2005. Effects of dexamethasone on Muc5ac mucin production by primary airway goblet cells. Am. J. Physiol. Lung Cell. Mol. Physiol., 288(1):L52-60.

Lv, Q. 2016. Glucocorticoid combined with hyaluronic acid enhance glucocorticoid receptor activity through inhibiting $\mathrm{p}$ 38MAPK signal pathway activation in treating acute lung injury in rats. Eur. Rev. Med. Pharmacol. Sci., 20(18):39203929.

Maron-Gutierrez, T., Castigtione, R.C., Xisto, D.G., Oliveira, M.G., Cruz, F.F., Pecanha, R., Carreira-Junior, H., Ornellas, D.S., Moraes, M.O., Takiya, C.M., Rocco, P.R. and Morales, M.M. 2011. Bone marrow-derived mononuclear cell therapy attenuates silica-induced lung fibrosis. Eur. Respir. J., 37(5): 12171225.

Montgomery, H.A. and Dymock, J.F. 1961. The determination of nitrite in water. Analyst, 86: 414.

Nejad-Moghaddam, A., Ajdary, S., Tahmasbpour, E., Rad, F.R., Panahi, Y. and Ghanei, M. 2016. Immunomodulatory properties of mesenchymal stem cells can mitigate oxidative stress and inflammation process in human mustard lung. Biochem. Genet., 54(6):769-783.

Quinton, P.M. 2010. Role of epithelial $\mathrm{HCO}_{3}$ transport in mucin secretion: lessons from cystic fibrosis. Am. J. Physiol. Cell Physiol., 299(6):C1222-33.

Robey, I.F., Baggett, B.K., Kirkpatrick, N.D., Roe, D.J., Dosescu, J., Sloane, B.F., Hashim, A.I., Morse, D.L., Raghunand, N., Gatenby, R.A. and Gillies, R.J. 2009. Bicarbonate increases tumor $\mathrm{pH}$ and inhibits spontaneous metastases. Cancer Res., 69(6): 2260-2268.

Rojas, M., Cardenes, N., Kocyildirim, E., Tedrow, J.R., Caceres, E., Deans, R., Ting, A. and Bermudez, C. 2014. Human adult bone marrow-derived stem cells 
decrease severity of lipopolysaccharideinduced acute respiratory distress syndrome in sheep. Stem Cell Res. Ther., $5(2): 42$.

Rubenfeld, G.D., Caldwell, E., Peabody, E., Weaver, J., Martin, D.P. Neff, M., Stern, E.J. and Hudson, L.D. 2005. Incidence and outcomes of acute lung injury. $N$. Engl. J. Med., 353:1685-1693

Shalaby, S.M., El-Shal, A.S., Abd-Allah, S.H., Selim, A.O., Selim, S.A., Gouda, Z.A., Abd El Motteleb, D.M., Zanfaly, H.E., El-Assar, H.M. and Abdelazim, S. 2014. Mesenchymal stromal cell injection protects against oxidative stress in Escherichia coli-induced acute lung injury in mice. Cytotherapy, 16(6):76475.

Shen,W., Gan, J., Xu, S., Jiang, G. and Wu, H. 2009. Penehyclidine hydrochloride attenuates LPS-induced acute lung injury involvement of NF-kappaB pathway. Pharmacol. Res., 60: 296-302.

Uddin, N., Hasan, M.R., Hasan, M.M., Hossain, M.M., Alam, M.R., Hasan, M.R., Islam, A.F., Rahman, T. and Rana, M.S. 2014. Assessment of toxic effects of the methanol extract of Citrus macroptera Montr. Fruit via biochemical and hematological evaluation in female sprague-dawley rats. PLoS One, 9(11):e111101.

Wagner, J. G., Hotchkiss, J. A. and Harkema, J. R. 2002a. Enhancement of nasal inflammatory and epithelial responses after ozone and allergen coexposure in brown norway rats. Toxicol. Sci., 67(2): 284-294.

Wagner, J.G., Van Dyken, S.J., Wierenga, J.R., Hotchkiss, J.A. and Harkema, J.R. 2003.
Ozone exposure enhances endotoxininduced mucous cell metaplasia in rat pulmonary airways. Toxicol. Sci., 74(2):437-46.

Wagner, J.G., Birmingham, N.P., JacksonHumbles, D., Jiang, Q., Harkema, J.R. and Peden, D.B. 2014. Supplementation with $\gamma$-tocopherol attenuates endotoxininduced airway neutrophil and mucous cell responses in rats. Free Radic. Biol. Med., 68:101-109.

Weiss, D.J. and Sueblinvong, V. 2009. Cell therapy approaches for lung diseases: current status. Curr. Opin. Phamacol., 9:268-273.

Xu, J., Woods, C.R., Mora, A.L., Joodi, R., Brigham, K.L., Iyer, S. and Rojas, M. 2007. Prevention of endotoxin-induced systemic response by bone marrowderived mesenchymal stem cells in mice. Am. J. Physiol. Lung Cell. Mol. Physiol., 293(1):L131-L141.

Yu, Z., Ouyang, J.P. and Li, Y.P. 2009. Dexamethasone attenuated endotoxininduced acute lung injury through inhibiting expression of inducible nitric oxide synthase. Clin. Hemorheol. Microcirc., 41(2): 117-125.

Zehendner, C.M., Luhmann, H.J. and Yang, J.W. 2013. A simple and novel method to monitor breathing and heart rate in awake and urethane-anesthetized newborn rodents. PLoS One, 8(5): e62628.

Zhao, L.L., Hu, G.C., Zhu, S.S., Li, J.F. and Liu, G.J. 2014. Propofol pretreatment attenuates lipopolysaccharide-induced acute lung injury in rats by activating the phosphoinositide-3-kinase/Akt pathway. Braz. J. Med. Biol. Res., 47(12): 10621067.

\section{How to cite this article:}

Hanaa - Mansour, A., Maha G. Soliman, Wedad A. Hasan, Rasha A. El-Sayed and Nahla A. Hassaan. 2018. Impact of Mesenchymal Stem Cells on Lipopolysaccharide-Induced Apoptosis in Acute Lung Injury Rat Model. Int.J.Curr.Microbiol.App.Sci. 7(06): 1254-1268. doi: https://doi.org/10.20546/ijcmas.2018.706.148 